\title{
Experimental Study on the Tensile Property of a Novel Oriented Linear Porous Metal
}

\author{
Bin Liu, ${ }^{1}$ Xin-gang Wang, ${ }^{2}$ Yong Tang, ${ }^{1}$ Wei Yuan, ${ }^{1}$ Chao-bin Fang, ${ }^{1}$ and Zhen-ping Wan ${ }^{1}$ \\ ${ }^{1}$ School of Mechanical and Automotive Engineering, South China University of Technology, Guangzhou 510640, China \\ ${ }^{2}$ China Academy of Space Technology (Xian), Xian 710000, China
}

Correspondence should be addressed to Yong Tang; ytang@scut.edu.cn

Received 25 August 2015; Accepted 29 November 2015

Academic Editor: Hossein Moayedi

Copyright (C) 2016 Bin Liu et al. This is an open access article distributed under the Creative Commons Attribution License, which permits unrestricted use, distribution, and reproduction in any medium, provided the original work is properly cited.

\begin{abstract}
A novel oriented linear porous metal (OLPM) with high porosity was fabricated through solid-sintering method with cutting copper fibers. In this study, tensile experiments were conducted to investigate the fracture process of the OLPM and the effects of porosity and sintering parameters on the tensile properties. The typical tensile stress-strain plot of this material was obtained based on a large number of tensile test results. The plot can be divided into three stages, namely, initial linear elastic stage, plastic deformation stage, and tensile fracture stage. Based on the results, the fracture mechanism of the OLPM was further studied. Moreover, the porosity and sintering parameters were also varied to investigate their influence on the tensile properties. Tensile strength and plastic deformation were found to decrease with increasing porosity ranging from $70 \%$ to $90 \%$. A higher sintering temperature produced a higher tensile strength for the OLPM sintered in the temperature range of $700^{\circ} \mathrm{C}-900^{\circ} \mathrm{C}$, but the strength decreased at $1000^{\circ} \mathrm{C}$. In addition, the extension of holding time could also slightly affect the tensile strength. Finally, the tensile properties of the OLPM are significantly higher than those of commercial porous metal and porous metal fiber sintered sheet.
\end{abstract}

\section{Introduction}

Porous metals with unique structural and functional properties have received extensive attention because of the interesting combinations of their outstanding thermal, acoustic, electrical, and mechanical properties [1,2]. Porous metal fiber sintered sheet (PMFSS), which is a new type of porous metal, has a three-dimensional reticulated structure characterized by high porosity and large specific surface area, and this material exhibits great potential for various applications in industry. To date, PMFSS is being widely used in defense and military, petrochemical industry, metallurgical machinery, environmental protection for its excellent performance in filtration and separation [3], flow field and gas diffusion [4], energy absorption [5], biomedical device [6], catalytic reaction [7, 8], heat transfer [9], and other applications. With the expansion of their application fields and the increasing complexity of their working environment, some special requirements for their properties of porous metals are becoming increasingly strict. In this study, a novel oriented linear porous metal (OLPM) with oriented linear porous structure and large porosity feature was produced, and this material has shown good potential in flow distribution and pressure drop, and it has been used in methanol steam reforming and presented a good performance $[10,11]$.

To broaden the application of this material, the relationship between its mechanical properties and its special structure should be elucidated.

In the past decades, many research groups have given significant attention to the fabrication, characterization, and application of porous metals $[12,13]$. Thus far, many studies have developed new fabrication methods and improved the mechanical properties of porous metals. Markaki and Clyne $[14,15]$ produced novel porous sheets using liquid phase sintering method of short stainless steel fibers with $100 \mu \mathrm{m}$ diameter. They found that the porous sheets had a porosity varying from $75 \%$ to $95 \%$ and a tensile strength below $1 \mathrm{MPa}$. Liu et al. $[16,17]$ developed a porous steel wire mesh material with open porosities prepared by the metallurgical route. The effect of the forming pressure and sintering parameters on the porous structure and mechanical behavior were further discussed. Moreover, Xi et al. [18, 19] fabricated a PMFSS 
using the vacuum sintering of stainless steel fibers with a diameter of $100 \mu \mathrm{m}$, and they introduced several methods to study the compressive and shear properties of PMFSS. Recently, Jin et al. [20] proposed a two-dimensional micromechanics random beam model to investigate the elastic-plastic behavior of PMFSS. In our previous studies [21-23], the tensile, compressive, and shear properties of the PMFSS have been investigated through experimental testing and microstructure observation method. These results provide an effective guideline in improving the design and manufacture methods of PMFSS for different engineering applications.

However, only a few studies have been conducted in the field of oriented linear porous metal. Huang et al. [24] fabricated a kind of porous copper with long cylindrical pores through directional solidification, and the compressive properties were investigated through experimental methods. Liu et al. [25] fabricated lotus-type porous copper bars with $45 \mathrm{~mm}$ diameter and $120 \mathrm{~mm}$ length through unidirectional solidification and the compressive deformation process was investigated, and the deformation mechanism was analyzed and discussed.

The above reported studies show that detailed research on the tensile properties of oriented linear porous metal using cutting metal fibers is lacking in the current literatures. This study investigated the tensile fracture process of this material produced by the solid-sintering of copper fibers. After the microstructures are examined, the tensile properties of the oriented linear porous metal are further analyzed and discussed by varying the porosity and sintering parameters. Finally, the tensile property of OLPM was compared with the commercial porous metal and the PMFSS.

\section{Experimental Procedure}

2.1. Manufacturing Process of OLPM. As reported previously [10], the preparation of oriented linear porous metal mainly includes three processes, namely, the fabrication of cutting fibers, the mold-pressing of parallel fibers, and the sintering with high temperature in a protective gas atmosphere.

First, long copper fibers were fabricated by a multitooth tool on a horizontal lathe. Figure 1 shows the schematic drawing of the multitooth tool; Figure 2 shows the fiber manufacturing process. The tool was installed on the turret with a setting angle of 45 degrees, and it has multiple tiny teeth fabricated through wire electrical discharge machining for achieving the simultaneous fabrication of multiple fibers. The distance and height of the tiny teeth were $0.3 \mathrm{~mm}$ and $0.2 \mathrm{~mm}$, respectively. The diameter of the cutting fibers was approximately $100 \mu \mathrm{m}$. The cutting fibers were collected by twining the fibers in a slab parallel to one another.

Second, the copper fibers were cut into several segments with fixed length of $120 \mathrm{~mm}$. Thereafter, multiple segments of copper fibers were uniformly arranged in parallel and put into the packing chamber of a mold pressing equipment, in which multiple stainless steel plates patterned with hollow chamber were first stacked and then tightened with four screws and two end plates. Through this means, the semifinished OLPM

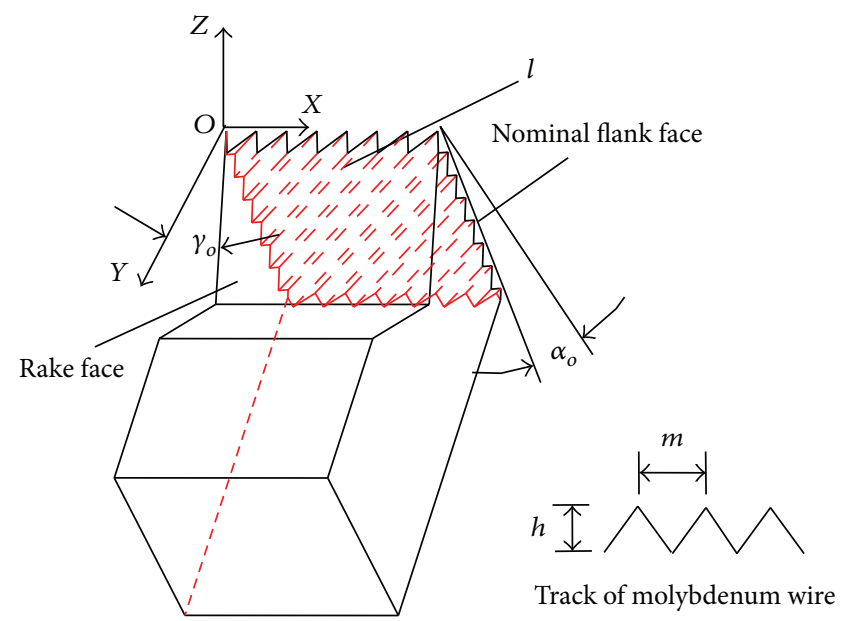

FIgURE 1: Schematic drawing of the multitooth tool.

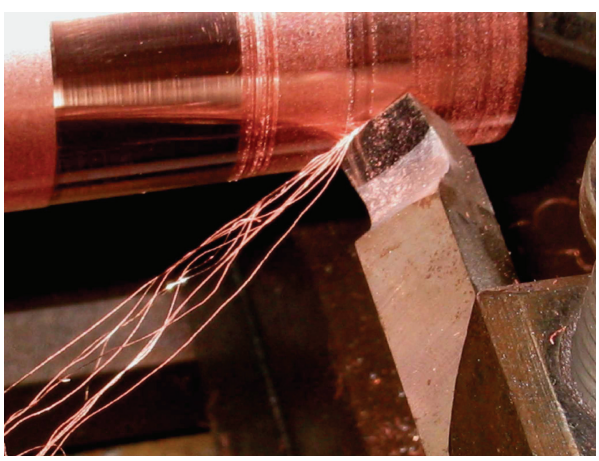

FIGURE 2: In situ photo of copper fiber manufacturing.

with the same shape as the predetermined packing chamber was obtained.

Later, the mold pressing equipment was put into a boxtype furnace, which provided the hydrogen gas atmosphere with a constant pressure of $0.3 \mathrm{MPa}$. The sintering temperature was set in the range of $700^{\circ} \mathrm{C}$ to $1000^{\circ} \mathrm{C}$ and was controlled by a programmable temperature controller. Stage heating method was used to optimize the heating rate. The heating rate was kept at $300^{\circ} \mathrm{C} / \mathrm{h}$ when the temperature was below $800^{\circ} \mathrm{C}$, whereas it reduced to $200^{\circ} \mathrm{C} / \mathrm{h}$ as the temperature rose above $800^{\circ} \mathrm{C}$. The holding times were set as $30 \mathrm{~min}, 60 \mathrm{~min}, 90 \mathrm{~min}$, or $120 \mathrm{~min}$. When the sintering process was completed, the furnace was cooled to $150^{\circ} \mathrm{C}$, and then the mold pressing equipment was taken out of the furnace and continued to cool down to room temperature. Lastly, the mold pressing equipment was disassembled and hence the OLPM with uniform thickness was formed.

The average porosity of the OLPM can be calculated using the quality-volume method formulated by the following because the obtained porous metal has a regular geometric shape:

$$
\theta(\%)=\left(1-\frac{M}{\rho V}\right) \times 100,
$$


where $\theta$ is the porosity of the porous metal, $V$ is the volume of the porous metal $\left(\mathrm{cm}^{3}\right), M$ is the mass of the porous metal $(\mathrm{g})$, and $\rho$ is the density of red copper $\left(\mathrm{g} / \mathrm{cm}^{3}\right)$.

The dimension of the OLPM sample is $120 \mathrm{~mm} * 15 \mathrm{~mm} *$ $2 \mathrm{~mm}$. Before being tested, the sample was cleaned ultrasonically with acetone for $5 \mathrm{~min}$ and then with deionized water for $5 \mathrm{~min}$; finally, it was left to dry in air at ambient temperature. The microscopic morphology of the OLPM was observed using a scanning electron microscope (JSM-6380LA, Japan).

2.2. Tensile Test of OLPM. The tensile test was carried out on a PC-controlled electronics universal testing machine (RGL$20 \mathrm{~A}$ ) with a maximum load of $20 \mathrm{kN}$, performing both test control and data acquisition. Before test, the sample was clapped in the machine to make sure that the test part was $60 \mathrm{~mm}$ in length. To avoid the deformation of the threedimensional network structure in the clamping process, rubber pads were placed between clamps. All the samples were pulled to failure at a constant tensile rate of $1.5 \mathrm{~mm} / \mathrm{min}$; and the tensile direction was the same with the direction of metal fibers. During each test, the load and displacement were recorded continuously. The strain is defined as the ratio between the sample elongation and the initial gauge length. The tensile stress is calculated by dividing the pulling force by the initial section of the sample. The maximum stress in the stress-strain plots was determined as the tensile strength of the OLPM. In order to obtain an accurate value of tensile strength, three specimens were tested in each case, and the average was taken.

\section{Results and Discussion}

3.1. Microstructure of OLPM. The SEM image of the OLPM sintered at $800^{\circ} \mathrm{C}$ for $30 \mathrm{~min}$ is shown in Figure 3. It can be seen from Figure 3 that there are many sintering joints and pore structures in the OLPM. The contact points among metal fibers transferred into sintering joints and formed the pore structure and the three-dimensional network structure of the OLPM during the sintering process. The pore structure formed among the parallel fibers and sintering joints showed different appearance, like long strip pore structure and point pore structure, but they are all along with the direction of the metal fiber. We can get a wide range of porosity (60\%-98\%) by changing the quantity of metal fibers and the molding pressure.

By further investigation of Figure 3, we can see that there are many microstructures on the surface of metal fibers. These rough surface morphologies are the unique features of the OLPM compared with other commercial porous metals shown in Figure 4. The surface of the metal fiber in the Biało et al. research is also very smooth [26]. These metal fibers are fabricated by melt-extraction [27] or bundle drawing method [28].

What is more, the rough surface can favor the sintering joints and improve the mechanical properties of the oriented linear porous metal. The rough surface increases the friction between fibers and provides an additional occlusal force that makes the fibers bond tightly, thus forming a relatively

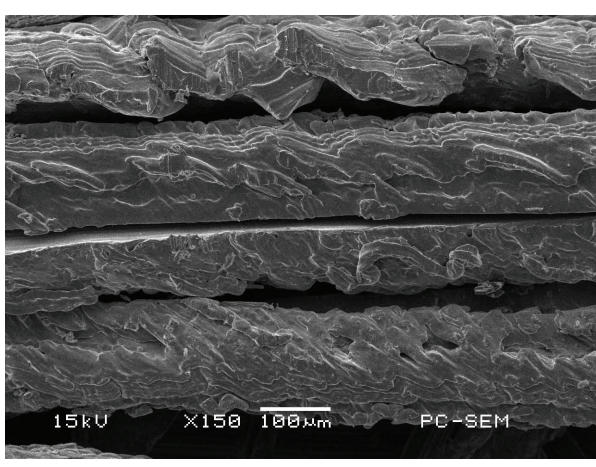

FIgURE 3: SEM image of the OLPM.

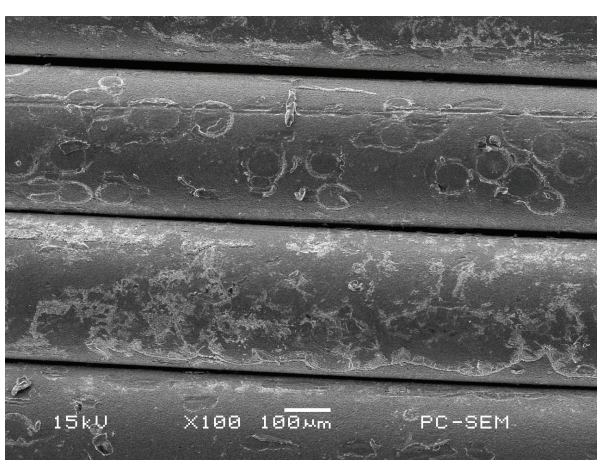

Figure 4: SEM image of the CPM.

strong structure. More importantly, the rough surface can provide higher specific surface area and can promote adhesive strength of the primer to the metallic support when the OLPM is used as catalyst support $[10,11]$.

3.2. Tensile Fracture Process of OLPM. Figure 5 shows the representative tensile stress-strain curve of an OLPM sample with $70 \%$ porosity sintered at $700^{\circ} \mathrm{C}$ for $30 \mathrm{~min}$. It can been seen from this figure that the tensile behavior of the OLPM sample can be divided into three stages: (a) initial linear elastic stage, (b) plastic deformation stage, and (c) fracture stage, which correspond to $\mathrm{OA}, \mathrm{AB}$, and $\mathrm{BC}$ in the curve, respectively.

The figure shows that the engineering stress increased linearly with the increasing strain in the initial stage, namely, the OA part of the plot. This process only lasts for a short time, and the elastic deformation of this sample is about $2 \%$. The relationship between stress and strain fits well with Hooke's law of elasticity. That is to say, in the initial elastic process, the oriented linear porous metal elongated in the tensile direction, and only a slight deformation occurs on the three-dimensional reticulation.

After the elastic process, the sample reaches the plastic deformation process quickly. In this stage, deformation begins to occur in some metal fibers first, where the local stress concentration occurs, fibers reach the yield limitation first, and the plastic deformation starts here. The local plastic deformation results in stress release and redistribution, which leads to a greater plastic deformation of more fibers with 


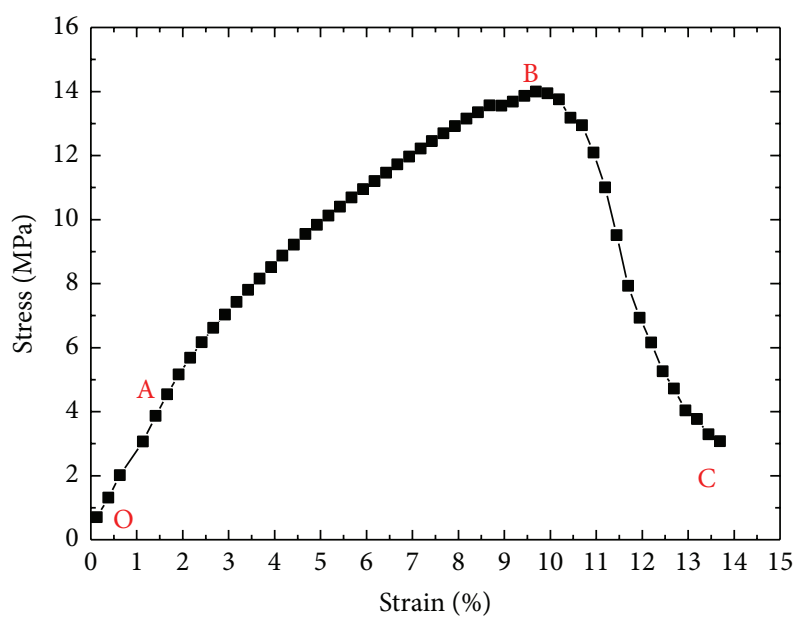

FIgURE 5: Typical tensile stress-strain curve of an oriented linear porous metal sample.

tension continuously increasing. As the plastic deformation capacity of the three-dimensional reticulated skeleton is exhausted, the stress reached the ultimate tensile strength.

With the fracture of the metal fiber gradually evolving into the sintering joint and the entire three-dimensional reticulated structure, the three-dimensional structure becomes prone to fracture. And the porous metal reaches the fracture stage; the engineering stress decreased sharply with the increasing strain in this stage; and this phenomenon lasts until the structure cannot undertake any load. And finally, the sample fails completely.

3.3. Tensile Fracture Mechanism of OLPM. To get a better understanding of the fracture of the OLPM, the facture mechanism of this new material was investigated in this study. The fracture process and the fractured samples were observed and analyzed.

The fracture image of the OLPM in the thickness direction was shown in Figure 6. It is clearly shown in Figure 6 that the fracture region becomes thicker and looser than any other part of the material because the fracture process first occurs in the surface of the material, where the restriction of the fibers is relatively smaller than that in the center of the material and where the deformation is larger than that in the center.

In addition, an obvious necking phenomenon is observed in the width direction along with the tensile load during the fracture process, as shown in Figure 7. This figure indicates that the oriented linear porous metal is a typical plastic material. Besides that, there is no obvious fracture trace in the fracture region of the OLPM. These phenomena are quite different from our previous studies with PMFSS [21], which is also a porous material made from metal fiber. This phenomenon can be caused by the following reasons. First, the metal fibers in the OLPM are parallel to one another, and the sintering joints are also found along with the direction of the metal fiber; that is, all the metal fibers in the OLPM are almost in the same condition, and this condition is good for the material to maintain the plastic property of the metal fiber itself. Figure 8 shows the fracture morphology of metal

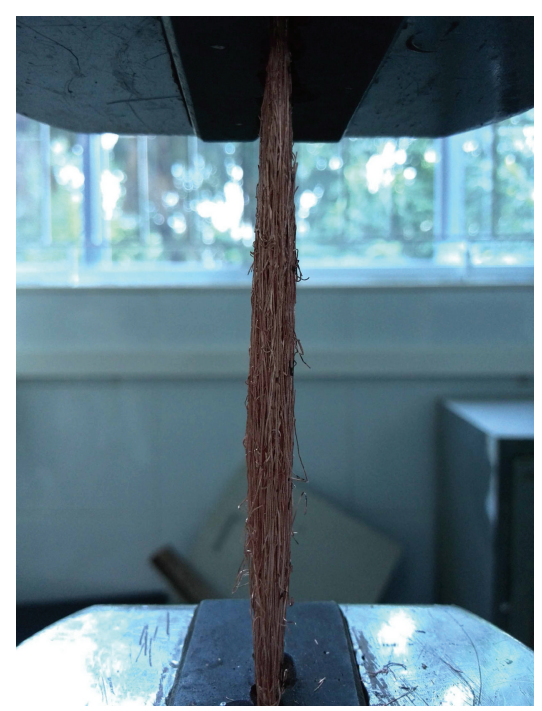

FiguRE 6: Fracture image of the OLPM in the thickness direction.

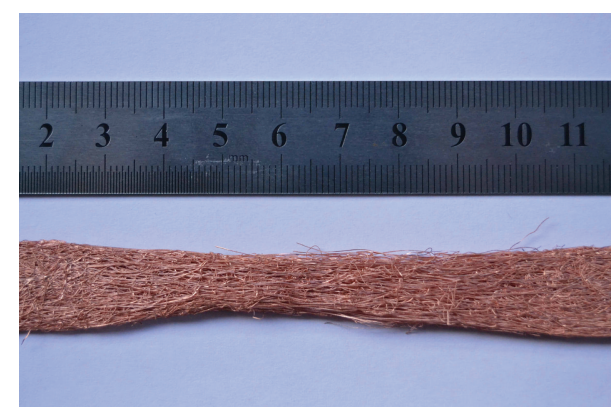

FIGURE 7: Appearance of the fractured OLPM.

fibers in the OLPM. It clearly shows that the metal fiber also undergoes a necking deformation under the tensile strength and maintains the original performance itself. Second, unlike the PMFSS, no fiber-to-fiber cross sintering joints and no pore structure perpendicular to the fiber direction restrict the elongation and deformation in the load direction. So the material can extend in the tensile direction. This structure is helpful to strengthen the mechanical properties and the ductility of the OLPM.

3.4. Influence of Porosity. Porosity is one of the most important factors of porous metals, and it greatly influences the mechanical properties of porous metals $[29,30]$. To analyze the influence of porosity on the tensile property of the OLPM, a single factor experiment was conducted. Three kinds of OLPM sintered at $800^{\circ} \mathrm{C}$ for $30 \mathrm{~min}$ with porosities of $70 \%$, $80 \%$, and $90 \%$ were used to investigate the effect of porosity on the tensile property.

Figure 9 shows the tensile stress-strain plots of the OLPM with different porosities sintered at $800^{\circ} \mathrm{C}$ for $30 \mathrm{~min}$. The tensile strength of the OLPM decreases greatly with the increase of porosity. As shown in Figure 8, the tensile strength of the sample with $70 \%$ porosity is $16.68 \mathrm{MPa}$, whereas those 


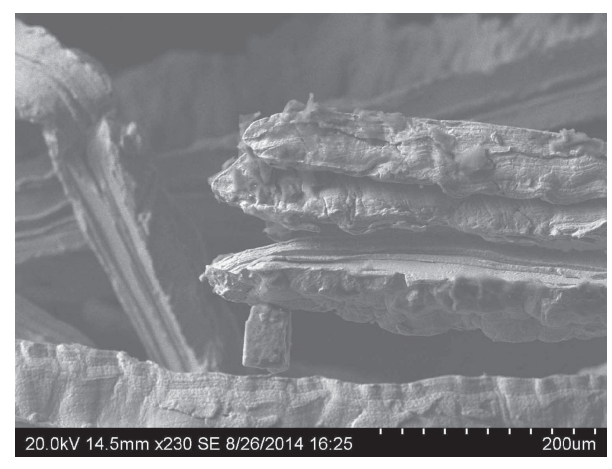

FIGURE 8: SEM image of fractured metal fibers in OLPM.

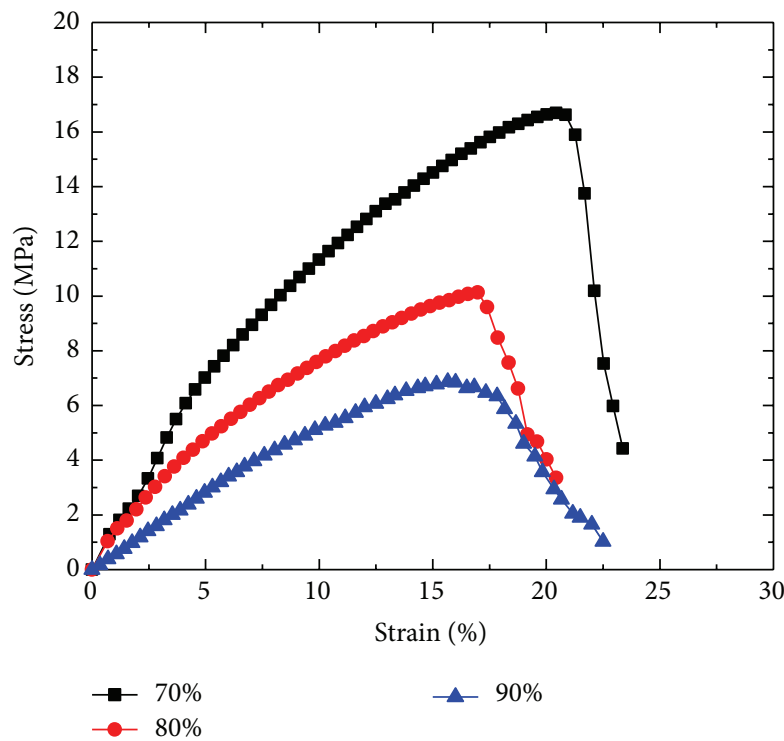

FIGURE 9: Tensile stress-strain curves of the oriented linear porous metal with different porosities.

of the samples with the porosities of $80 \%$ and $90 \%$ are only $10.12 \mathrm{MPa}$ and $7.37 \mathrm{MPa}$, respectively. This result fits well with the result of Qiao et al. [19]. This result is mainly attributed to the following two aspects. On the one hand, the OLPM sample with lower porosity has more fibers and sintering joints in its cross-section to withstand the tensile force. Conversely, the sample with higher porosity has less fibers and contact regions to form sintering joints. On the other hand, in order to obtain high porosity, sparse fibers are distributed in the mold and low compaction force is applied, which hinder the formation of solid-sintering joints and lead to the sintering joints weaker than those of low porosity. And the stress concentration first occurs at them. These two aspects both result in low tensile strength in high porosity.

In addition, Figure 9 also illustrates that the sample with lower porosity shows a longer plastic stage. The total deformation of OLPM with $70 \%$ porosity is $20.85 \%$, while the ductility of OLPMs with $80 \%$ and $90 \%$ porosity is $16.97 \%$ and $15.66 \%$, respectively. That is because higher porosity means less metal fibers in the OLPM, and the faster the fracture

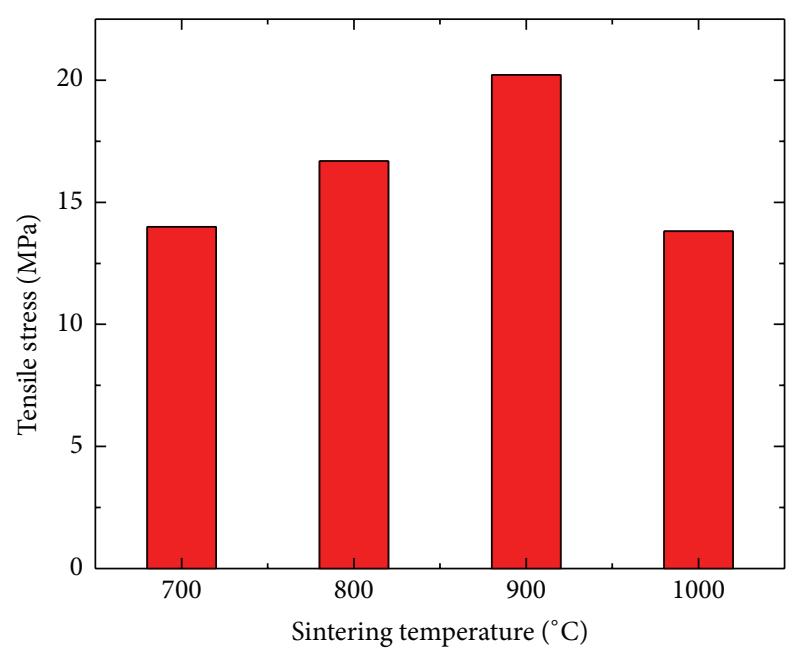

FIGURE 10: Tensile strength of the oriented linear porous metal with different sintering temperatures.

process transfer into the three-dimensional structure of the OLPM, the smaller the deformation of the whole process.

After the plastic deformation stage, the fracture rates of the samples with different porosities are not identical. The stress-strain curve of the sample with lower porosity drops more sharply, which means that the sample fractures faster.

3.5. Influence of Sintering Parameters. As important manufacturing parameters, sintering temperature and sintering time greatly influence the forming process of the oriented linear porous metal.

3.5.1. Sintering Temperature. Four samples with $70 \%$ porosity sintered at $700^{\circ} \mathrm{C}, 800^{\circ} \mathrm{C}, 900^{\circ} \mathrm{C}$, and $1000^{\circ} \mathrm{C}$ for 30 min were selected to investigate the influence of sintering temperature on the tensile strength of the oriented linear porous metal. Figure 10 shows the tensile strength plot of the OLPM samples sintered at different temperatures.

Obviously, the tensile strength of the OLPM increases with sintering temperatures between $700^{\circ} \mathrm{C}$ and $900^{\circ} \mathrm{C}$, but it decreases at $1000^{\circ} \mathrm{C}$. This mainly because the formation of sintering joints is controlled by atom diffusion, which is a random thermal motion. High sintering temperature increases the energy of copper atoms [31,32]. On the one hand, it increases the number of activated copper atoms and the opportunity of copper fibers forming the sintering joints. On the other hand, it is beneficial for the migration of copper atoms, thus accelerating the sintering process [33]. Therefore, the number of sintering joints increases and sintering joints grow larger. These phenomena will lead to the improvement of the tensile property of the OLPM. Therefore, in the range of $700^{\circ} \mathrm{C}$ to $900^{\circ} \mathrm{C}$, the tensile strength increases with sintering temperature. However, during the sintering process, the metal fiber undergoes a heat treatment process, the increasing sintering temperature enlarges the grain size of the copper fiber when the temperature is higher than the recrystallization temperature, and the microstructure on the surface of the metal fiber will disappear at high temperature 


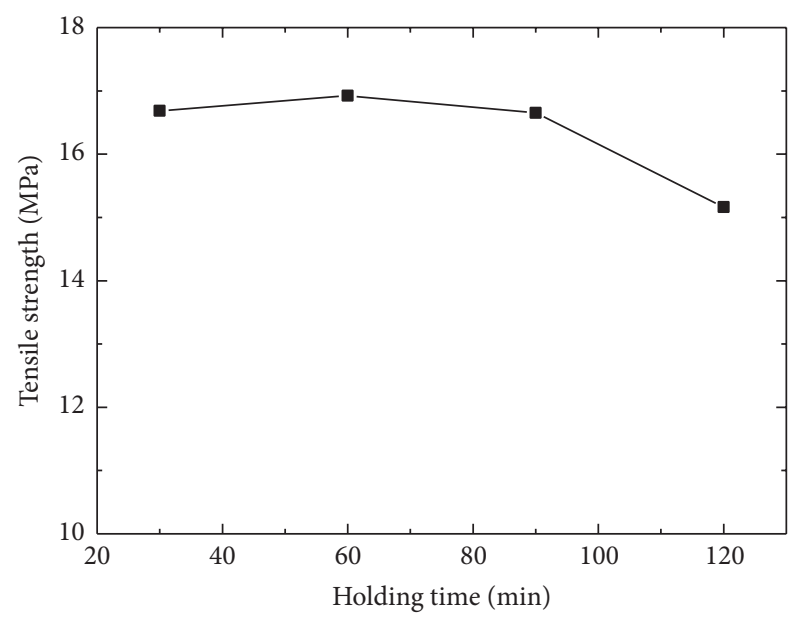

FIgURE 11: Tensile strength of the oriented linear porous metal with different holding times.

[34]. These phenomena will all lead to the decrease of tensile property at $1000^{\circ} \mathrm{C}$. This situation provides us with a guide that a reasonable sintering temperature to fulfill different requirements could be chosen.

3.5.2. Holding Time. The tensile property of the porous metal with the porosity of $70 \%$ sintered at $800^{\circ} \mathrm{C}$ for $30 \mathrm{~min}, 60 \mathrm{~min}$, $90 \mathrm{~min}$, and $120 \mathrm{~min}$ is shown in Figure 11. From Figure 11, we can conclude that holding time has slight effect on the tensile property of OLPM. When the sintering time was extended from $30 \mathrm{~min}$ to $60 \mathrm{~min}$, the tensile strength increased from 16.68 $\mathrm{MPa}$ to $16.92 \mathrm{MPa}$. However, the sintering time of 60 min leads to the maximum tensile strength at the sintering temperature of $800^{\circ} \mathrm{C}$, and the tensile strength decreases to 16.65 $\mathrm{MPa}$ and $15.16 \mathrm{MPa}$ when the sintering time increases to $90 \mathrm{~min}$ and $120 \mathrm{~min}$, respectively. The difference between different holding time is $11 \%$.

The results are caused by the following two aspects. On the one hand, sintering joints formed between fibers become larger with the increase of sintering time, leading to the improvement of the tensile properties of the porous metal. Meanwhile, the increase of sintering time caused the grain of the copper fibers to become coarse, leading to the decrease in the mechanical property of the fiber itself and then to the decrease of the tensile properties of the material. The combination of the two aspects leads to the result. In addition, the lengthening of the sintering time increases the manufacturing cost of the oriented linear porous metal. Therefore, improving the tensile strength of the porous metal by extending the sintering time is not logical.

3.6. Comparing with Commercial Porous Metal and PMFSS. The tensile strength of the oriented linear porous metal was compared with the commercial porous metal and the porous metal fiber sintered sheet [21]. Figure 12 shows the tensile strengths of three kinds of materials sintered at $800^{\circ} \mathrm{C}$ for $30 \mathrm{~min}$ and $60 \mathrm{~min}$ with $80 \%$ porosity. The figure shows that the tensile strength of the OLPM is significantly higher than those of the other two kinds of materials. This result is because

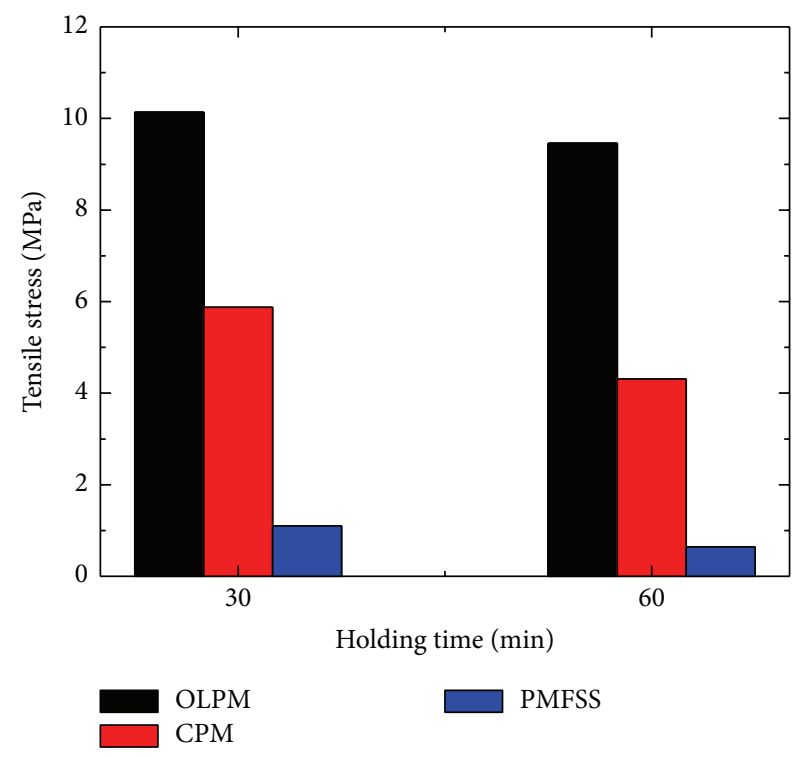

FIgURE 12: Tensile strength of three different porous metals.

that the surface of the metal fiber in CPM is smooth, as shown in Figure 4. It is relatively difficult for the metal fiber to form sintering joints between the smooth surfaces [35], so the tensile strength is relatively lower than that of the oriented linear porous metal. The metal fibers in the PMFSS occlude one another, and not all the metal fibers can resist the tension force, so the tensile strength is significantly lower than that of the oriented linear porous metal.

These results obtained provide us with an important technical guideline for different potential applications of the OLPM, especially for the conditions with the tensile loading.

\section{Conclusion}

(1) A novel oriented linear porous metal with a threedimensional network structure was produced through the solid-state sintering method with cutting copper fibers. With a special long strip pore structure and numerous microstructures on the surface of the metal fiber, this material exhibits unique properties during the tensile fracture process. And the tensile process of the OLPM included the following three stages: the elastic stage at low strain, the plastic deformation stage, and the damage and fracture of the overall network structure.

(2) The tensile strength depends heavily on the porosity. The tensile strength of the OLPM decreased rapidly with the increasing porosity, and the extent of the deformation increases with the decreasing porosity.

(3) The sintering parameters also play important role in the tensile properties of the OLPM. The tensile strength increases with sintering temperature from $700^{\circ} \mathrm{C}$ to $900^{\circ} \mathrm{C}$ and then decreases at $1000^{\circ} \mathrm{C}$. The extension of holding time slightly affected the tensile strength of the OLPM, and $900^{\circ} \mathrm{C}$ is the optimal sintering temperature of this material.

(4) The tensile strength of the OLPM is much higher than the PMFSS and the CPM. The results obtained in this work 
provide an important technical guideline for different potential applications of the OLPM, especially for the conditions with the tensile loading.

\section{Conflict of Interests}

The authors declare that there is no conflict of interests regarding the publication of this paper.

\section{Acknowledgment}

This work was supported by the National Natural Science Foundation of China (Grants nos. 51275180 and 51475172).

\section{References}

[1] L.-P. Lefebvre, J. Banhart, and D. C. Dunand, "Porous metals and metallic foams: current status and recent developments," Advanced Engineering Materials, vol. 10, no. 9, pp. 775-787, 2008.

[2] G. J. Davies and S. Zhen, "Metallic foams: their production, properties and applications," Journal of Materials Science, vol. 18, no. 7, pp. 1899-1911, 1983.

[3] A. Nabovati, E. W. Llewellin, and A. C. M. Sousa, "A general model for the permeability of fibrous porous media based on fluid flow simulations using the lattice Boltzmann method," Composites Part A: Applied Science and Manufacturing, vol. 40, no. 6-7, pp. 860-869, 2009.

[4] J.-K. Kuo and C.-K. Chen, "A novel Nylon-6-S316L fiber compound material for injection molded PEM fuel cell bipolar plates," Journal of Power Sources, vol. 162, no. 1, pp. 207-214, 2006.

[5] Z. Bo and C. Tianning, "Calculation of sound absorption characteristics of porous sintered fiber metal," Applied Acoustics, vol. 70, no. 2, pp. 337-346, 2009.

[6] G. Ryan, A. Pandit, and D. P. Apatsidis, "Fabrication methods of porous metals for use in orthopaedic applications," Biomaterials, vol. 27, no. 13, pp. 2651-2670, 2006.

[7] W. Yuan, Y. Tang, X. Yang, and Z. Wan, "Toward using porous metal-fiber sintered plate as anodic methanol barrier in a passive direct methanol fuel cell," International Journal of Hydrogen Energy, vol. 37, no. 18, pp. 13510-13521, 2012.

[8] Y. Tang, W. Zhou, M. Q. Pan, H. Q. Chen, W. Y. Liu, and H. $\mathrm{Yu}$, "Porous copper fiber sintered felts: an innovative catalyst support of methanol steam reformer for hydrogen production," International Journal of Hydrogen Energy, vol. 33, no. 12, pp. 2950-2956, 2008.

[9] A. S. Abduljalil, Z. B. Yu, and A. J. Jaworski, "Selection and experimental evaluation of low-cost porous materials for regenerator applications in thermoacoustic engines," Materials and Design, vol. 32, no. 1, pp. 217-228, 2011.

[10] M. Q. Pan, Y. Tang, X. L. Wei, and J. Xiang, "Oriented linear cutting fiber sintered felt as an innovative catalyst support for methanol steam reforming," International Journal of Hydrogen Energy, vol. 36, no. 12, pp. 7066-7073, 2011.

[11] M. Q. Pan, X. L. Wei, and Y. Tang, "Factors influencing methanol steam reforming inside the oriented linear copper fiber sintered felt," International Journal of Hydrogen Energy, vol. 37, no. 15, pp. 11157-11166, 2012.
[12] J. Banhart, "Manufacture, characterisation and application of cellular metals and metal foams," Progress in Materials Science, vol. 46, no. 6, pp. 559-632, 2001.

[13] H. Nakajima, "Fabrication, properties and application of porous metals with directional pores," Progress in Materials Science, vol. 52, no. 7, pp. 1091-1173, 2007.

[14] A. E. Markaki, V. Gergely, A. Cockburn, and T. W. Clyne, "Production of a highly porous material by liquid phase sintering of short ferritic stainless steel fibres and a preliminary study of its mechanical behaviour," Composites Science and Technology, vol. 63, no. 16, pp. 2345-2351, 2003.

[15] T. W. Clyne, A. E. Markaki, and J. C. Tan, "Mechanical and magnetic properties of metal fibre networks, with and without a polymeric matrix," Composites Science and Technology, vol. 65, no. 15, pp. 2492-2499, 2005.

[16] P. Liu, G. He, and L. H. Wu, "Fabrication of sintered steel wire mesh and its compressive properties," Materials Science and Engineering A, vol. 489, no. 1-2, pp. 21-28, 2008.

[17] P. Liu, G. He, and L. Wu, "Uniaxial tensile stress-strain behavior of entangled steel wire material," Materials Science and Engineering A, vol. 509, no. 1-2, pp. 69-75, 2009.

[18] Z. P. Xi, H. P. Tang, J. Y. Wang, Y. J. Wu, L. F. Dong, and B. J. Yang, "Study on the mechanical properties of porous metals," Rare Metal Materials and Engineering, vol. 36, pp. 555-558, 2007.

[19] J. C. Qiao, Z. P. Xi, H. P. Tang, J. Y. Wang, and J. L. Zhu, "Compressive behavior of porous metal fibers," Rare Metal Materials and Engineering, vol. 37, no. 12, pp. 2173-2176, 2008.

[20] M. Z. Jin, C. Q. Chen, and T. J. Lu, “The mechanical behavior of porous metal fiber sintered sheets," Journal of the Mechanics and Physics of Solids, vol. 61, no. 1, pp. 161-174, 2013.

[21] W. Zhou, Y. Tang, M. Q. Pan, X. L. Wei, and J. H. Xiang, "Experimental investigation on uniaxial tensile properties of high-porosity metal fiber sintered sheet," Materials Science and Engineering A, vol. 525, no. 1-2, pp. 133-137, 2009.

[22] W. Zhou, Y. Tang, B. Liu et al., "Compressive properties of porous metal fiber sintered sheet produced by solid-state sintering process," Materials \& Design, vol. 35, pp. 414-418, 2012.

[23] Z. Wan, B. Liu, W. Zhou, Y. Tang, K. S. Hui, and K. N. Hui, "Experimental study on shear properties of porous metal fiber sintered sheet," Materials Science and Engineering A, vol. 544, pp. 33-37, 2012.

[24] F. Huang, T.-W. Yang, Z.-J. Li, Z.-H. Li, Q.-L. Jin, and R. Zhou, "Anisotropic compressive properties of ordered porous copper," The Chinese Journal of Nonferrous Metals, vol. 21, no. 3, pp. 604610, 2011.

[25] X.-H. Liu, D. Yao, X.-F. Liu, and J.-X. Xie, "Deformation behaviors and constructive relation of lotus-type porous copper under compressive direction perpendicular to pores," The Chinese Journal of Nonferrous Metals, vol. 19, no. 7, pp. 1237-1244, 2009.

[26] D. Biało, L. Paszkowski, W. Wiśniewski et al., "Properties of high porosity structures made of metal fibers," in Recent Advances in Mechatronics, pp. 470-474, Springer, Berlin, Germany, 2007.

[27] N. I. Baik, Y. Choi, and K. Y. Kim, "Fabrication of stainless steel and aluminum fibers by PDME method," Journal of Materials Processing Technology, vol. 168, no. 1, pp. 62-67, 2005.

[28] R. De Bruyne, "Bundle-drawn metal fibers," Advanced Materials and Processes, vol. 147, no. 6, pp. 33-34, 1995.

[29] P. S. Liu, "Mechanical relations for porous metal foams under several typical loads of shearing, torsion and bending," Materials Science and Engineering A, vol. 527, no. 29-30, pp. 7961-7966, 2010. 
[30] P. S. Liu, T. F. Li, and C. Fu, "Relationship between electrical resistivity and porosity for porous metals," Materials Science and Engineering A, vol. 268, no. 1-2, pp. 208-215, 1999.

[31] R. M. German, Sintering Theory and Practice, Wiley, New York, NY, USA, 1996.

[32] P. Wang, The Powder Metallurgy, Metallurgical Industry Press, Beijing, China, 1997.

[33] J. Pan and A. C. F. Cocks, "A numerical technique for the analysis of coupled surface and grain-boundary diffusion," Acta Metallurgica et Materialia, vol. 43, no. 4, pp. 1395-1406, 1995.

[34] X. L. Wei, M. Q. Pan, D. H. Dehuai, Q. Wang, Y. Tang, and W. Zhou, "Effect of heating temperature on microstructure and mechanical properties of continuous copper fiber," in Proceedings of the International Conference on Industrial Mechatronics and Automation (ICIMA '09), pp. 475-478, IEEE, Chengdu, China, May 2009.

[35] D. Gouvêa and R. H. R. Castro, "Sintering: the role of interface energies," Applied Surface Science, vol. 217, no. 1-4, pp. 194-201, 2003. 

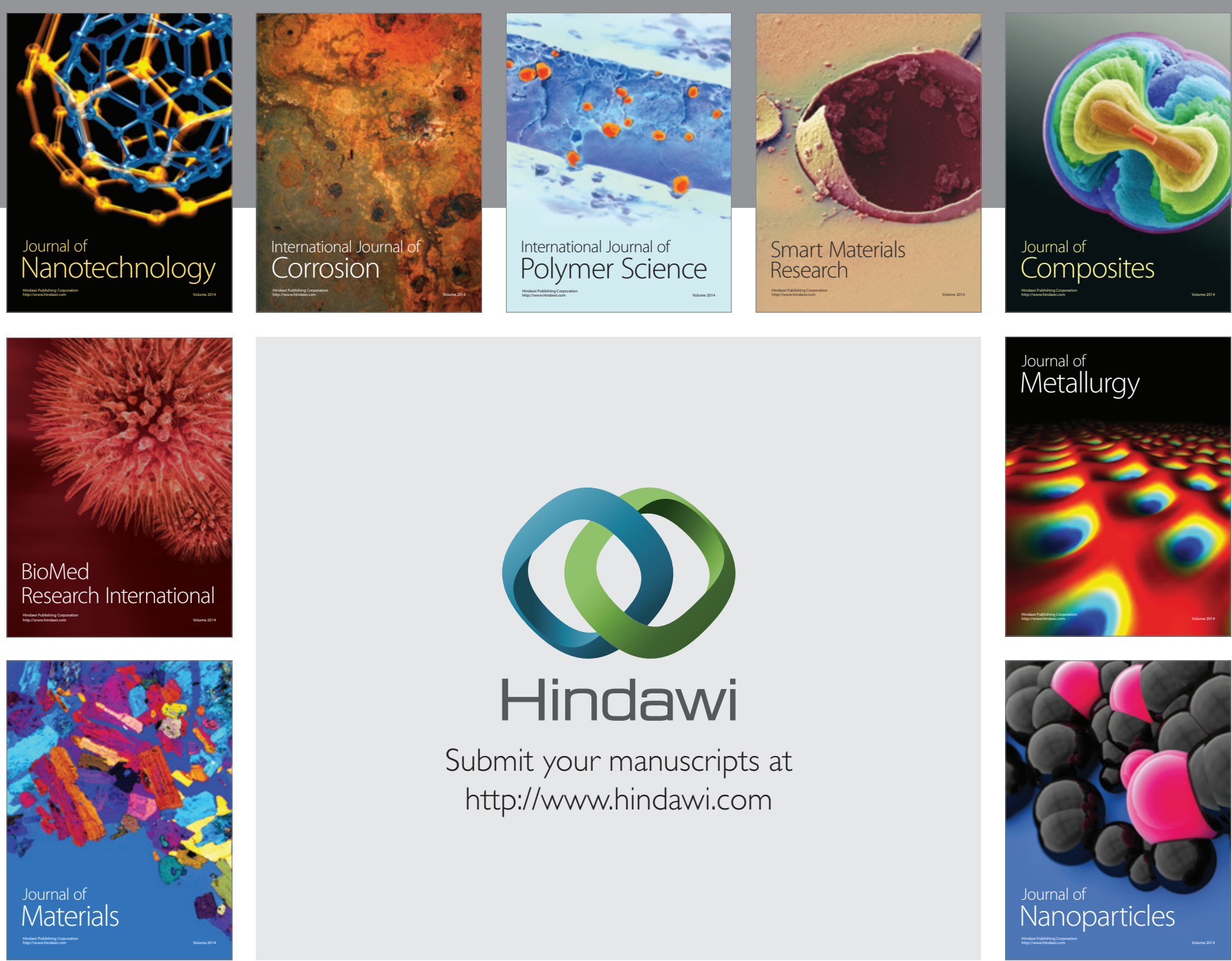

\section{Hindawi}

Submit your manuscripts at

http://www.hindawi.com

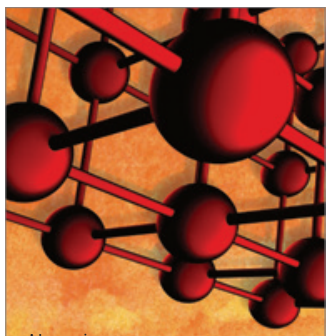

Materials Science and Engineering
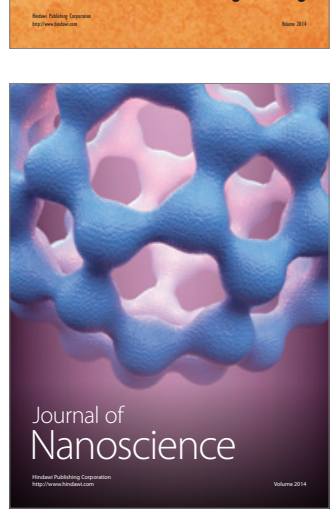
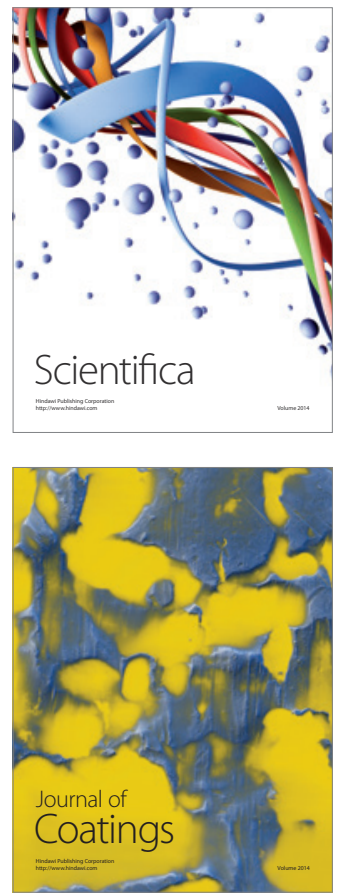
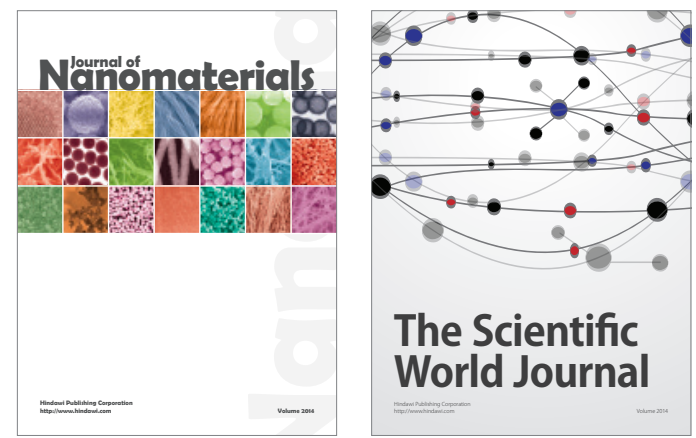

The Scientific World Journal
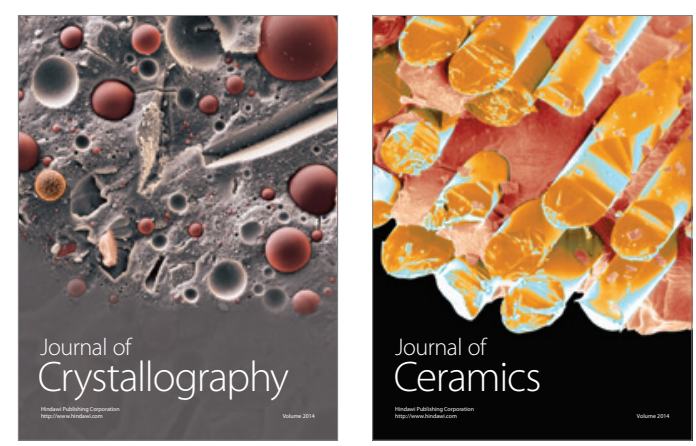
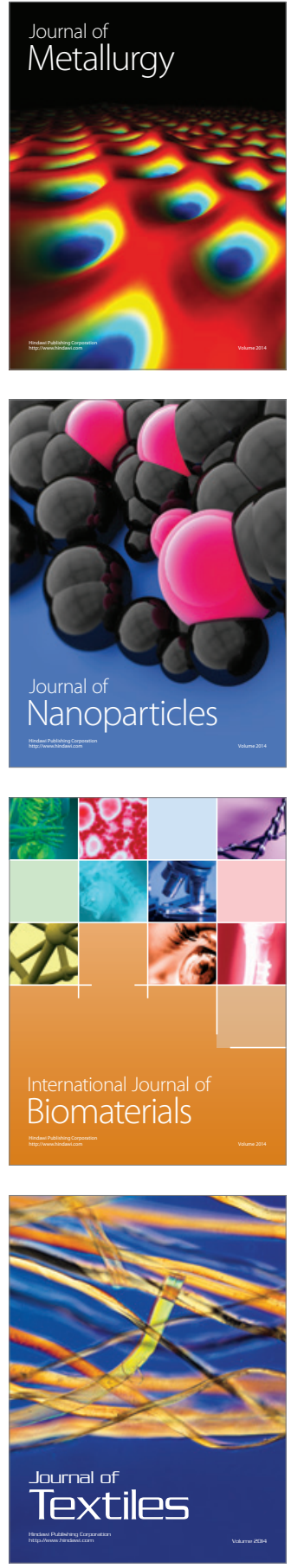